\title{
DETEKSI IMAGE SPLICING PADA CITRA DENGAN METODE DISCRETE COSINE TRANSFORM (DCT) DAN SCALE INVARIANT FEATURE TRANSFORM (SIFT)
}

\author{
Endina Putri Purwandari ${ }^{1}$, Arie Vatresia ${ }^{2}$, Sudarti Siburian ${ }^{3}$ \\ ${ }^{1,2,3}$ Program Studi Informatika, Fakultas Teknik, Universitas Bengkulu \\ Jl. W.R. Supratman Kandang Limun Bengkulu 38371A Indonesia \\ (Telp : 0736-341022; fax: 0736-341022) \\ ${ }^{1}$ endinaputridunib.ac.id \\ 2arie.vatresia@unib.ac.id \\ ${ }^{3}$ sudartysimatupang@gmail.com
}

Abstrak: Pemalsuan terhadap citra digital sangat sering terjadi pada perkembangan teknologi sekarang ini. Image splicing adalah salah satu metode yang paling umum yang digunakan untuk melakukan kegiatan pemalsuan citra. Tujuan penelitian ini adalah membangun aplikasi deteksi image splicing pada citra dengan metode Discrete Cosine Transform (DCT) dan Scale Invariant Feature Transform (SIFT). Penelitian tentang deteksi image splicing dengan kombinasi metode DCT dan SIFT belum pernah dilakukan sebelumnya. Aplikasi ini meng-convert citra dari RGB ke bentuk graysacle. Kemudian menerapkan metode Discreate Cosine Transform untuk mencari frekuensi pada citra grayscale lalu menggunakan metode Scale Invarian Feature Transform untuk mendeteksi keypoint yang sama pada citra, dan menerapkan metode RANSAC untuk menghilangkan outlier pada citra. Aplikasi ini dibangun menggunakan bahasa pemprograman matlab. Data citra yang digunakan dalam penelitian ini ada sebanyak 20 citra, yaitu 10 citra dari internet dan 10 citra koleksi pribadi. Hasil pengujian fungsional sistem melalui metode Black Box telah berhasil $100 \%$ dengan skenario yang telah dibuat. Berdasarkan hasil pengujian yang telah dilakukan nilai akurasi pada deteksi image splicing dengan citra dari internet sebesar $100 \%$, dan nilai akurasi pada deteksi dengan citra koleksi pribadi sebesar $100 \%$. Hasil dari penelitian ini diharapkan dapat digunakan oleh masyarakat untuk membedakan citra yang asli dengan citra yang mengalami pemalsuan image splicing.

Kata Kunci: pemalsuan citra, image splicing, keypoint, DCT,SIFT, RANSAC. 


\begin{abstract}
Counterfeiting of digital images is very common in today's technological developments. Image joining is one of the most commonly used methods for image forgery. The purpose of this research is to develop a splicing detection application on images using the Discrete Cosine Transform (DCT) and Scale Invariant Feature Transform (SIFT) methods. Research on the detection of connecting images using the DCT and SIFT combination methods has never been done before. This application converts images from RGB to graysacle. Then use the Discreate Cosine Transform method to find the frequency in grayscale images, then use the Scale Invariant Feature Transform method to convert the same keypoint to the image, and use the RANSAC method to eliminate outliers in the image. This application was built using the matlab programming language. Image data used in this study amounted to 20 images, namely 10 images from the internet and 10 images of private collections. The functional system test results through the Black Box method have been 100\% successful with the scenarios that have been made. Based on the results of tests that have been carried out the value on detection of splicing images with images from the internet is $100 \%$, and the accuracy value on detection with images of private collections is $100 \%$. The results of this study are expected to be used by the public to improve the original image with an image that improves the falsification of the splicing image.

Keywords: image falsification, image splicing, keypoint, DCT, SIFT, RANSAC.
\end{abstract}

\section{Pendahuluan}

Pemalsuan terhadap citra digital pada perkembangan teknologi sekarang ini sangat sering terjadi. Hal ini dapat menimbulkan permasalahan dalam kehidupan sosial bermasyarakat seperti hilangnya kepercayaan terhadap suatu berita, pencemaran nama baik, perusakan terhadap reputasi seseorang, pemalsuan barang bukti dan masih banyak permasalahan lainnya. Pemalsuan citra adalah proses manipulasi pada sebagian atau seluruh daerah citra baik terhadap isi maupun konteks citra dengan bantuan teknik pemrosesan citra digital [1].

Image splicing adalah salah satu metode yang umum digunakan untuk melakukan kegiatan memodifikasi gambar. Dalam situsnya University of Columbia menyatakan bahwa image splicing atau pemotongan gambar dilakukan dengan cara memotong bagian tertentu pada gambar lalu memindahkannya atau menggandakannya kepada gambar lain.

Penelitian terkait dengan pengolahan citra pernah dilakukan sebelumnya oleh Wahyu Restuty Tresnaningsih, Endina Putri Purwandari, dan Desi Andreswari [2] yang melakukan penelitian tentang Deteksi Pemalsuan Citra Copy Move Menggunakan Dyadic Wavelet dan Scale Invariant Feature Transform yang mampu mendeteksi serangan postprocessing dengan metode pemalsuan rotasi dan skala (diperbesar dan diperkecil) yang diterapkan pada citra uji. Penelitian Deteksi Pemalsuan Citra Dengan Teknik Copy-Move menggunakan Metode Ordinal Measure Dari Koefisien Discrete Cosine Transform oleh Zulfan, Fitri Arnia dan Rusdha Muharar [3] yang dapat mendeteksi pemalsuan copy move dibuktikan dengan ditemukannya blokblok fitur pada objek citra yang dicurigai telah dicopy move yang memiliki jarak lebih kecil dari nilai ambang batas pendeteksian.

Penelitian lainnya tentang deteksi pemalsuan copy-move pada citra digital pernah juga dilakukan oleh Ela Gusvita Sari Damanik, Boko Susilo, Endina Putri [4]. Penelitian ini menggunakan metode Discrete Cosine Transform (DCT) dan Scale Invariant Feature Transform (SIFT) yang mencapai nilai akurasi sebesar $100 \%$. Penelitian lainnya tentang Image Splicing Detection Based On Demosaicking and Wavelet Transformation oleh Endina Putri Purwandari [1] yang dapat memperkirakan citra input adalah citra asli atau citra palsu dan memperkirakan wilayah citra masukan yang telah mengalami manipulasi digital. Penelitian tentang Splicing Detection for Combined DCT, DWT and Spatial MarkovFeatures Using Essemble Classifier oleh Rachna Mehta dan Navneet Agarwal [5] yang mampu 
mencapai akurasi sebesar $99.85 \%$ pada treshold dengan nilai $\mathrm{E}=1$.

Penelitian tentang Ekstraksi Fitur Berbasis 2DDiscrete Cosine Transform dan Principical Component Analysis Untuk Pengenalan Citra Wajah oleh Arif Muntasa dan Mochamad Kautshar Sophan [6], yaitu jika semakin banyak jumlah fitur yang digunakan untuk pengukuruan kemiripan, maka semakin tinggi akurasi pengenalnnya, meskipun untuk titik-titik fitur tertentu, terkadang akurasinya menurun. Serta Penelitian tentang Pengenalan Barang Pada Kereta Belanja Menggunakan Metode Scale Invariant Feature Transform (SIFT) yang dapat mengenali barang dalam citra kereta belanja dengan tingkat akurasi rata-rata $48.89 \%$ berdasarkan jumlah barang dan jarak pengambilan gambar oleh Ronny Makhfuddin Akbar dan Nani Sunarmi [7] .

\section{LANDASAN TEORI}

\section{A. Citra}

Secara harafiah, citra gambar adalah gambar pada dwimatra atau dua dimensi [8]. Citra dapat digolongkan menjadi 2 golongan, yaitu citra kontinu dan citra diskrit. Citra kontinu dihasilkan oleh optik yang menerima sinyal analog, misalnya kamera analog, mata manusia. Sedangkan citra diskrit diperoleh melalui proses digitalisasi pada citra kontinu. Beberapa sistem optik dilengkapi dengan fungsi digitalisasi sehingga mampu untuk menghasilkan citra diskrit, misalnya kamera digital dan scanner. Citra diskrit disebut juga citra digital.

\section{B. Resolusi Citra}

Resolusi citra merupakan tingkat detailnya suatu citra. Semakin tinggi resolusinya semakin tinggi pula tingkat detail dari citra tersebut [9]. Menurut Sutoyo [10] ada dua jenis resolusi yang perlu diketahui, yaitu:

Resolusi Spasial dan resolusi kecemerlangan. Resolusi spasial merupakan ukuran halus atau kasarnya pembagian kisi-kisi baris dan kolom pada saat sampling. Sedangkan resolusi kecemerlangan atau biasanya disebut dengan kedalaman bit/ kedalaman warna (Bit Depth) adalah ukuran halus kasarnya pembagian tingkat gradasi warna saat dilakukan kuantisasi. Kualitas citra merupakan tingkatan piksel suatu citra, dimana semakin besar piksel suatu citra maka kualitas citra yang dihasilkan semakin baik. Karena ika citra itu diperbesar,citra yang dihasilkan tidak pecah\& terlihat kotak-kotak piksel yang menyusunnya [11].

\section{Image Splicing Forgery}

Pemalsuan citra digital adalah citra yang telah mengalami manipulasi pada perubahan isi dan konteks [1]. Pemalsuan citra digital memiliki banyak kesamaan dengan pemalsuan foto konvensional. Namun, dibandingkan memanipulasi film atau negatif analog. Pemalsuan digital dilakukan dengan mengubah data digital yang dimiliki suatu citra. Program komputer seperti Adobe Photoshop, GIMP dan Corel Paint Shop telah membuat perubahan pada foto digital menjadi luar biasa mudah, didukung oleh kemampuan, kehandalan dan harga yang murah dari program program tersebut, bahkan beberapa diantaranya dapat diperoleh secara gratis.

Ada beberapa tipe pemalsuan digital. Setiap tipe pemalsuan merupakan bagian dari tiga kategori utama, tergantung pada proses yang digunakan dalam pengkreasian citra. Kategori pemalsuan terdiri dari Image Splicing dan Copy-Move. Copymove adalah proses menyalin salah satu bagian dari citra dan menyisipkannya ke bagian lain pada citra yang sama dengan posisi yang berbeda [12]. Cropping (pemotongan) adalah memotong satu bagian dari citra sehingga diperoleh citra yang berukuran lebih kecil. Proses ini bertujuan untuk memisahkan objek yang satu dengan objek yang lain dalam suatu gambar untuk mempercepat proses selanjutnya [13]. Image Splicing adalah suatu 
bentuk manipulasi gambar digital dengan menggabungkan 2 atau lebih gambar menjadi gambar yang baru [1].

\section{Discrete Cosine Transform (DCT)}

Discrete Cosine Transfrom atau yang biasa disingkat DCT adalah satu kelas operasi matematika yang termasuk Dalam Fast Fourier Transfrom. Operasi dasar yang ditampilkan dalam transformasi DCT adalah mengambil suatu signal dan mentransformasikannya dari reprentasi satu tipe ke tipe yang lain [14]. Transformasi ini dikerjakan secara frekuentatif yaitu dengan cara mengambil suatu nilai dari domain spasial dan mentransformasikannya kedalam suatu representasi yang identik.

Dalam hal ini DCT digunakan sebagai metode untuk ekstraksi fitur yaitu untuk mencari frekuensi citra. DCT 2 dimensi ditampilkan dalam matriks $\mathrm{NxN}$, dan menghasilkan matriks NxN. Persamaan DCT 2 dimensi ini digunakan untuk transformasi matriks 2 dimensi. Dalam pembagian blok pada DCT, menurut Hernandez [15] LF menyatakan daerah koefisien frekuensi rendah, MF menyatakan daerah koefisien frekuensi menengah, dan HF menyatakan daerah koefisien frekuensi tinggi. Persamaan dari DCT 2 dimensi adalah sebagai berikut:

$$
\begin{gathered}
D C T(i, j)=\sqrt{\frac{2}{M}} \sqrt{\frac{2}{N}} C(i) C(j) . \\
\sum_{x=0}^{N-1} \sum_{y=0}^{N-1} \operatorname{pixel}(x, y) \cos \left[\frac{(2 x+1) i \pi}{2 M}\right] \cos \left[\frac{(2 y+1) i \pi}{2 N}\right]
\end{gathered}
$$

Dengan DCT $(i, j)=$ nilai DCT Pada indeks ke(i,j), $\mathrm{N}$ adalah ukuran baris matriks, $\mathrm{M}$ adalah ukuran kolom matriks. Pixel $(\mathrm{x}, \mathrm{y})$ adalah nilai pixel pada indeks ke-(x,y). Nilai C(i), C(j) $=1$ jika $1, \mathrm{j}>0$, dan nilai $\mathrm{C}(\mathrm{i}), \mathrm{C}(\mathrm{j})=\frac{1}{\sqrt{2}}$ jika $1, \mathrm{j}=0$. Menurut Fahmi [16] pada transformasi DCT dikenal juga istilah frekuensi rendah, frekuensi menengah, dan frekuensi tinggi. Hal ini berkaitan dengan frekuensi gelombang pada fungsi basis DCT. Jika frekuensi fungsi basisnya kecil, maka koefisien yang berkorespondensi disebut koefisien frekuensi rendah. Sesudah metode DCT dapat dilakukan quantization. Kuantisasi dilakukan untuk membersihkan koefisien DCT yang tidak penting untuk pembentukan image baru. Dimana frekuensi yang tinggi akan diseleksi untuk dihilangkan yang terikat pada pengaturan kualitas yang digunakan. Hal ini yang menyebabkan JPEG bersifat lossy [17].

\section{E. Scale Invariant Feature Transform (SIFT)}

Scale Invariant Feature Transform (SIFT) adalah sebuah algoritme dalam computer vision untuk mendeteksi dan mendeskripsikan fitur lokal dalam gambar [18]. Algoritme ini dipublikasikan oleh David Lowe pada tahun 1999. Dengan menggunakan SIFT ini, suatu citra akan diubah menjadi vector fitur local yang kemudian digunakan sebagai pendekatan dalam mendeteksi maupun mengenali objek yang dimaksud melalui keypoint [19]. Algoritme yang digunakan pada metode SIFT antara lain:

1. Pencarian Nilai Ekstrema pada Skala Ruang

Pencarian nilai ekstrim maksimum dan minimum pada skala ruang merupakan tahap awal dalam penentuan keypoint dari suatu citra. Dengan menggunakan fungsi Gaussian, citra pada skala ruang dapat didefinisikan sebagai fungsi $L(x, y, \sigma)$ yang diperoleh dari hasil konvolusi skala-variable Gaussian, $G(x, y, \sigma)$ dengan citra masukan $I(x, y)$ sehingga diperoleh [19].

$$
L(x, y, \sigma)=G(x, y, \sigma) * I(\mathrm{x}, \mathrm{y})
$$

Dimana * adalah operasi konvulasi antara $x$ dan $y$ dan $G(x, y, \sigma)$ adalah skala Variable Gaussian [20].

$$
G(x, y, \sigma)=\frac{1}{2 \pi \sigma^{2}} e^{-\left(x^{2}+y^{2}\right) / 2 \sigma^{2}}
$$


Citra hasil Difference of Gaussian, $D(x, y, \sigma)$, diperoleh dengan melakukan operasi konvolusi pada citra masukan dengan filter Difference of Gaussian, maka

$$
\begin{aligned}
D(x, y, \sigma)= & G(x, y k \sigma)-G(x, y \sigma) * \\
& I(x, y) \\
= & L(x, y, k \sigma)-L(x, y, \sigma)
\end{aligned}
$$

Dari persamaan di atas terlihat bahwa citra hasil Difference of Gaussian sebenarnya merupakan selisih antara citra hasil pengkaburan Gaussian dengan skala k yang berbeda.

Setelah diperoleh citra DoG pada setiap octave, maka langkah selanjutnya ialah mencari kandidat keypoint. Kandidat keypoint dideteksi sebagai titik maksimum dan minimum lokal dari citra hasil DoG. Proses penghilangan keypoint yang memiliki kontras rendah dilakukan dengan melihat area maksimal dan area minimal, jika nilai kurang dari treshold maka titik tersebut tidak menjadi keypoint.

\section{Penentuan Orientasi}

Pada tahap ini, masing-masing keypoint yang diperoleh akan diberikan suatu orientasi yang tetap berdasarkan sifat-sifat lokal pada citra. Dengan adanya proses ini maka keypoint yang diperoleh dapat direpresentasikan relatif terhadap orientasi ini sehingga keypoint yang dihasilkan tidak terpengaruh terhadap adanya rotasi pada citra.

$$
\theta(x, y)=\tan ^{-1}\left(\frac{L(x, y+1)-L(x, y-1)}{L(x+1, y)-L(x-1, y)}\right)
$$

\section{Deskriptor Keypoint}

Pada proses ini, masing-masing keypoint yang telah diorientasikan akan diberikan pencirian khusus (descriptor). Proses ini bertujuan untuk mendapatkan keypoint yang invarian terhadap perubahan itensitas cahaya atau perubahan sudut pandang tiga dimensi. Descriptor akan diukur sebagai suatu orientasi pada wilayah pixel dengan ukuran $4 \times 4$. Nilai orientasi diperoleh dari citra Gaussian yang memilki skala terdekat dengan skala keypoint yang akan dihitung. Keypoint yang diperoleh invariant terhadap orientasi, maka koordinat dari descriptor dan gradient orientasi akan dirotasi relatif terhadap orientasi dari keypoint. jendela deskriptor, akan digunakan sebagai pembebanan pada setiap besaran nilai dari titik sampel [19]

\section{F. RANSAC (Random Sample Consensu)}

\section{RANSAC (Random Sample Consensus)} merupakan metode yang digunakan untuk mencari Homography Matrix dan sekaligus berfungsi untuk menghilangkan outliers dari feature - feature yang telah ditemukan. Outliers sendiri merupakan feature yang memiliki nilai menyimpang dari kebanyakan feature lain [21]. RANSAC adalah algoritme untuk menemukan kelompok "inliers", yaitu point yang dipasangkan ke dalam garis. Ini adalah algoritme non-deterministik dalam pengertian bahwa RANSAC memproduksi hasil yang memuaskan dengan probabilitas tertentu .

Untuk menentukan jumlah dari iterasi yang dilakukan bisa didapat dari rumus:

$$
k=\frac{\log (1-p)}{\log \left(1-w^{n}\right)}
$$

Dimana $p$ merupakan probabilitas yang ditentukan oleh user sesuai dengan kebutuhan, dan w adalah jumlah inlier pada data dan $\mathrm{n}$ adalah jumlah point yang akan dipilih [22] .

\section{METODE PENELITIAN}

\section{A. Metode Pengumpulan Data}

Proses pengumpulan data pada penelitian ini menggunakan metode dokumentasi. Data citra image splicing yang digunakan diperoleh dari internet pada www.boombastis.com dan www.lettera43.it dan cita image splicing hasil editan sendiri atau koleksi pribadi.

\section{B. Alur Kerja Sistem}


Secara umum alur kerja aplikasi dimulai dengan memilih citra kemudian citra akan di-convert ke grayscale. Selanjutnya citra masukan dilakukan ekstraksi fitur untuk mencari frekuensi citra menggunakan metode Discrete Cosine Transform. Kemudian mencari keypoint yang sama dengan menggunakan metode SIFT, setelah mendapatkan keypoint yang sama pada cita kemudian digunakan metode RANSAC untuk menghilangkan outlier pada citra. Berikut ini diagram alur kerja aplikasi pada Gambar 1.

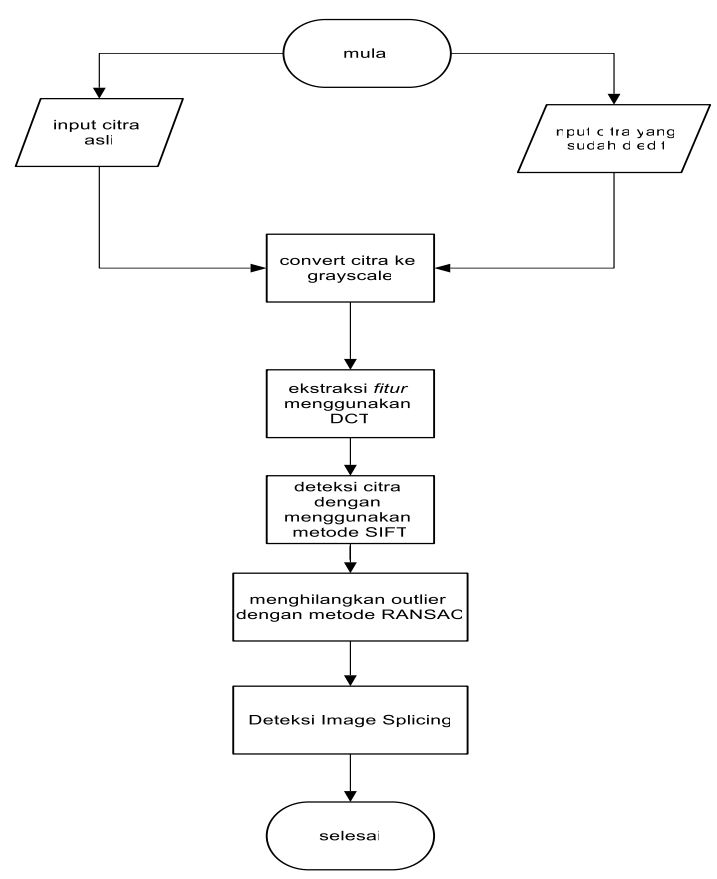

Gambar 1. Diagram alur kerja sistem

\section{Ekstraksi fitur menggunakan DCT}

Proses ekstraksi dengan metode DCT, yaitu mentransformasikan citra ukuran $m x n$ dari domain spasial ke domain DCT. DCT menyusun sinyal tersebut ke frekuensi spasial yang disebut dengan koefisien DCT. Frekuensi DCT yang lebih rendah muncul pada kiri atas dari sebuah matriks DCT, dan frekuensi koefisien lebih tinggi berada pada bawah kanan dari matriks DCT.

\section{Proses Deteksi Citra Image Splicing}

Menggunakan SIFT

Proses ini diawali dengan mengambil citra dengan hasil ekstraksi fitur dengan metode DCT sebagai masukan. Pada deteksi metode SIFT ini akan dihasilkan banyaknya keypoint, deskriptor keypoint dan lokasi keypoint dari citra yang diekstrak kemudian akan dilakukan pencocokan fitur dengan metode SIFT. Operasi pencocokan dijalankan pada setiap keypoint untuk mengidentifikasi jalur lokal yang memiliki kesesuaian.

Kandidat yang dianggap memiliki kesamaan untuk setiap keypoint ditemukan melalui identifikasi ketetanggan terdekat dari seluruh keypoint lainnya. Untuk menentukan apakah dua keypoint bersesuaian atau tidak, secara sederhana dilakukan evaluasi jarak antara dua deskriptor dengan menggunakan nilai distratio.Pada proses akhir akan ditampilkan hasil deteksi keypoint yang sama pada citra.

E. Proses Menghilangkan Outlier pada citra menggunakan metode RANSAC

Titik/keypoint yang bersesuaian dari hasil metode SIFT selanjutnya diproses menggunakan metode RANSAC (RANdom Sample Consensus). Dari proses ini nantinya dapat menghilangkan outlier pada citra hasil SIFT dan menunjukkan bagian citra yang mengalami image splicing.

Sesudah diterapkan metode DCT, SIFT dan RANSAC maka akan ditampilkan citra hasil deteksi image splicing pada citra.

\section{HASIL DAN PEMBAHASAN}

Data citra uji yang digunakan sebanyak 20 citra, yaitu citra dari internet sebanyak 10 dan cita editan sendiri sebanyak 10.

\section{Ekstrasi fitur citra dengan metode DCT}

Langkah pertama yang dilakukan dalam proses pendeteksian ini adalah, mengubah citra RGB ke grayscale. Sesudah di convert ke grayscale maka langkah selanjutnya yang dilakukan adalah menerapkan metode DCT untuk mencari frekuensi 
pada citra. Berikut adalah hasil output dari metode DCT pada citra yang diinput oleh user .

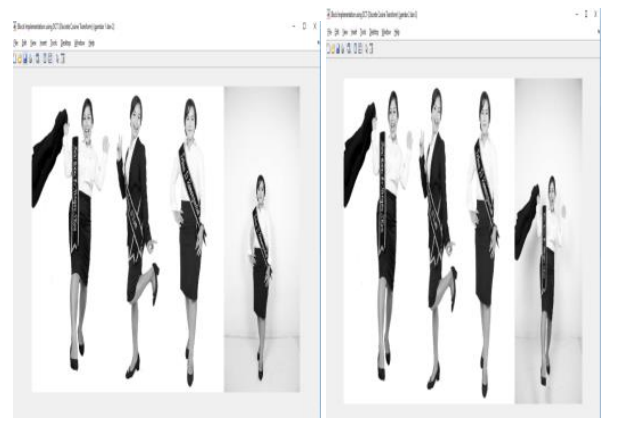

Gambar 2. Hasil Output Dari Metode Discrete Cosine Transform

\section{Menerapkan Metode SIFT}

Sesudah diterapkan metode DCT, langkah selanjutnya adalah menerapkan metode SIFT untuk mencari keypoint-keypoint yang sama pada citra, gambar 3 merupakan hasil output dengan metode SIFT pada citra. Ekstraksi fitur dengan metode SIFT ini dilakukan agar memperoleh keypoint yang merupakan suatu titik yang invariant terhadap ukuran, translasi, dan rotasi. Hasil ekstraksi fitur mencirikan secara khusus [23].

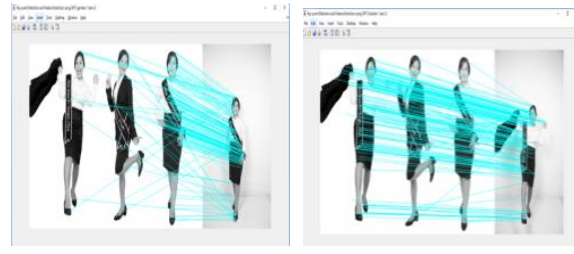

Gambar 3. Hasil output dari metode SIFT
3. Menerapkan Metode RANSAC untuk menghilangkan outlier pada citra

Sesudah diterapkan metode SIFT, langkah selanjutnya adalah menerapkan metode RANSAC untuk menghilangkan outlier pada citra. Gambar 4 merupakan hasil deteksi image splicing pada citra dengan menerapkan metode RANSAC pada citra yang sudah diproses dengan metode SIFT sebelumnya untuk menghilangkan outlier pada citra. Citra yang ditandai atau yang ditarik garis pada aplikasi ini adalah citra yang yang mengalami pemalsuan image splicing. Berikut adalah hasil outpjut dari metode RANSAC yang diterapkan pada citra.

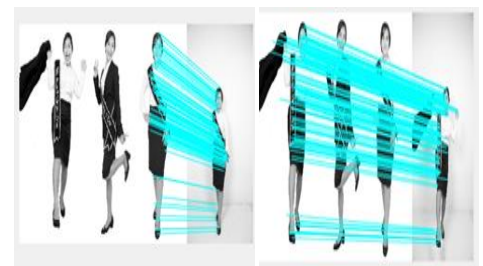

Gambar 4. Hasil output penerapan metode RANSAC pada citra.

Semua hasil pengujian dikatakan dikatakan berhasil apabila ditemukan minimal 7 keypoint yang sama pada citra. Hal ini sejalan dengan hasil penelitian Seok-Wun Ha dan Yong-Ho Moon [24] yang menyatakan bahwa location-matched pada objek jika ditemukan keypoint dimulai dari 7 keypoint.

A. Pengujian citra dari internet

Tabel 1. Pengujian citra dari datasheet www.boombastis.com dan www.lettera43.it

\begin{tabular}{|c|c|c|c|c|c|c|c|}
\hline No & Citra asli & Citra edit & Citra edit & Ukuran & Waktu & $\begin{array}{c}\text { Keypoint } \\
\text { matches }\end{array}$ & Keterangan \\
\hline 1 & & & - & $737 \times 737 ; 737 \times 690$ & 36,468 & 788 & Berhasil \\
\hline 2 & & & - & $737 \times 737 ; 737 \times 525$ & 29,125 & 229 & Berhasil \\
\hline 3 & & 8 & - & $737 \times 532 ; 737 \times 490$ & 20,437 & 134 & Berhasil \\
\hline
\end{tabular}


Jurnal Pseudocode, Volume V Nomor 2, September 2018, ISSN 2355-5920, e-ISSN 2655-1845 www.ejournal.unib.ac.id/index.php/pseudocode

\begin{tabular}{|l|l|l|l|l|c|c|}
\hline 4 & & & $737 \times 445,737 \times 836$ & 41,5 & 241 & Berhasil \\
\hline 5 & & & & & & \\
\hline
\end{tabular}

Berdasarkan Tabel 1 dapat dilihat bahwa waktu deteksi untuk citra yang memiliki ukuran lebih kecil lebih lama dibandingkan dengan citra yang memiliki ukuran piksel lebih besar sehingga dapat disimpulkan bahwa semakin besar ukuran piksel suatu citra maka akan semakin cepat juga proses pendeteksian image splicing di dalam aplikasi ini. Dari pengujian 10 citra yang berasal dari internet B. Pengujian citra koleksi pribadi yang diuji untuk mendeteksi pemalsuan image splicing pada Tabel 1. tingkat akurasi sistem adalah sebagai berikut :

$$
\text { akurasi }=\frac{10}{10} \times 100 \%=100 \%
$$

Terdapat beberapa faktor yang mempengaruhi keberhasilan sistem dalam mencocokkan citra, seperti latar belakang, kerapatan citra, kualitas citra dari masing- masing citra masukan [25].

Tabel 2. Tabel Pengujian citra koleksi pribadi

\begin{tabular}{|c|c|c|c|c|c|c|c|}
\hline No & Citra asli & Citra edit & Citra edit & Ukuran & Waktu & $\begin{array}{l}\text { Keypoint } \\
\text { matches }\end{array}$ & Keterangan \\
\hline 1 & & & & $737 \times 526 ; 737 \times 561$ & 17,031 & 62 & Berhasil \\
\hline 2 & & & & $737 \times 491 ; 737 \times 1107$ & 46,453 & 140 dan 751 & Berhasil \\
\hline 3 & & & & $737 \times 1106 ; 737 \times 984$ & 25,75 & 23 & Berhasil \\
\hline & & & & $737 \times 491 ; 737 \times 1241$ & 24,125 & 182 dan 175 & Berhasil \\
\hline 5 & & & & $737 \times 1278 ; 737 \times 983 ;$ & 37,843 & 344 dan 186 & Berhasil \\
\hline
\end{tabular}


Jurnal Pseudocode, Volume VI Nomor 2, September 2019, ISSN 2355-5920, e-ISSN 2655-1845 www.ejournal.unib.ac.id/index.php/pseudocode

\begin{tabular}{|l|r|r|r|l|l|l|}
\hline 6 & & & & \\
\hline
\end{tabular}


Jurnal Pseudocode, Volume V Nomor 2, September 2018, ISSN 2355-5920, e-ISSN 2655-1845 www.ejournal.unib.ac.id/index.php/pseudocode

Dari pengujian 10 citra koleksi pribadi yang diuji untuk mendeteksi pemalsuan image splicing pada tabel 2 , tingkat akurasi sistem adalah sebagai berikut :

$$
\text { akurasi }=\frac{10}{10} \times 100 \%=100 \%
$$

Berdasarkan tabel 2 dapat dilihat bahwa waktu deteksi untuk citra yang memiliki ukuran lebih kecil lebih lama dibandingkan dengan citra yang memiliki ukuran piksel lebih besar sehingga dapat disimpulkan bahwa semakin besar ukuran piksel suatu citra maka akan semakin cepat juga proses pendeteksian image splicing di dalam aplikasi ini.

\section{KESIMPULAN DAN SARAN}

\section{A. Kesimpulan}

Berdasarkan penelitian dan pembahasan hasil yang sudah dilakukan, maka terdapat beberapa kesimpulan yang diperoleh dari penelitian ini, diantaranya sebagai berikut :

1. Penelitian ini telah menghasilkan sebuah aplikasi deteksi pemalsuan image splicing dengan menggunakan metode Discrete Cosine Transform dan Scale Invariant Feature Transform (SIFT).

2. Aplikasi deteksi pemalsuan image splicing ini dengan keberhasilan pengujian citra dengan data dari internet $100 \%$, pengujian citra dengan data koleksi pribadi $100 \%$, dan running time pada aplikasi ini lebih cepat untuk citra yang memiliki ukuran piksel lebih besar dibandingkan dengan citra yang memiliki ukuran piksel kecil.

\section{B. Saran}

Berdasarkan hasil dan pembahasan yang telah dijabarkan sebelumnya, maka saran yang dapat diberikan untuk pengembangan penelitian selanjutnya adalah perlunya dilakukan prosesproses tambahan sebelum metode SIFT agar pendeteksian dan pencocokan keypoint dapat berjalan lebih bailk.

\section{REFERENSI}

[1] Purwandari, E. P. (2015). Image Splicing Detection Based on Demosaicking and Wavelet Transformation Vol 6, No.1. Journal of Computer Sience and Information , 27-35.

[2] Tresnaningsih, W. R., Purwandari, E. P., \& Andreswari, D. (2017). Deteksi Pemalsuan Citra Copy Move Menggunakan Dyadic Wavelet dan Scale Invariant Feature Transform. Jurnal Pseudocode, Volume IV Nomor 1 .

[3] Zulfan, Arnia, F., \& Muharar, R. (2016). Deteksi Pemalsuan Citra dengan Teknik Copy Move Menggunakan Metode Ordinal Measure Dari Koefisien Discrete Cosine Transform. Jurnal Nasional Teknik Elektro Vol: 5 No. 2 .

[4] Damanik, E. G., Susilo, B., \& P, E. P. (2017). Deteksi pemalsuan copy-move pada citra digital menggunakan metode Discrete Cosine Transform (DCT) dan Scale Invariant Feature Transform (SIFT) . Jurnal Teknologi Informasi, Volume 13 Nomor 1 .

[5] Mehta, R., \& Agarwal, N. (2018). Splicing Detection for Combined DCT, DWT and Spatial Markov-Features Using Ensemble Classifier. Procedia Computer Science .

[6] Muntasa, A., \& Sophan, M. K. (2009). Ekstraksi Fitur Berbasis 2D-Discrete Cosine Transform dan Principical Component Analysis Untuk Pengenalan Citra Wajah. Seminar Nasional Aplikasi Teknologi Informasi .

[7] Akbar, R. M., \& Sunarmi, N. (2018). Pengenalan Barang Pada Kereta Belanja Menggunakan Metode Scale Invariant Feature Transform (SIFT). Jurnal Teknologi Informasi dan Ilmu Komputer.

[8] Munir, R. (2004). Pengolahan Citra Digital dengan Pendekatan Algoritmik. Informatika Bandung.

[9] Putra, D. (2010). Pengolahan Citra Digital. Yogyakarta : Penerbit Andi.

[10]Sutoyo, T. ,. (2009). Teori Pengolahan Citra Digital. Yogyakarta: Penerbit Andi.

[11]Zhang, A., \& Gourley, D. (2008, September, Tuesday). Creating Digital Collections : A Practical Guide. Chandos Publishing.

[12]Ahmadi, A. (2014). Image Forgery Detection Exploting Image Randomness. Arab Saudi: King Saudi University. 
Jurnal Pseudocode, Volume VI Nomor 2, September 2019, ISSN 2355-5920, e-ISSN 2655-1845 www.ejournal.unib.ac.id/index.php/pseudocode

[13]Balza, A., \& Kartika, F. (2005). Teknik Pengolahan Citra Digital menggunakan Delphi. Yogyakarta: Ardi Publishing.

[14] Noviardhi, A. G. (2008). Komprensi Citra Menggunakan Metode Discrete Coisene Transform (DCT). Yogyakarta: Universitas Sanata Dharma.

[15]Hernandez, J. R. (2000). DCT-Domain Watermarking Techniques for Still Images: Detector Performance Analysis and a New Structure. IEEE TRANSACTIONS ON IMAGE PROCESSING, VOL. 9, NO. 1 .

[16]Fahmi. (2007). Studi dan Implementasi Watermarking Citra Digital dengan Menggunakan Fungsi Hash. Indonesia: Institut Teknologi Bandung.

[17]Prabowo, A., Sarwoko, E., \& Riyanto, D. (2006) Perbandingan Antara Metode Kohonen Neural Network dengan Metode Learning Vector Quantization Pada Pengenalan Pola Tandatangan. Jurnal Sains \& Matematika Vol.4, No.4

[18]Lowe, D. (2004). Distinctive Image Features from ScaleInvariant Keypoints. International Journal of Computer Vision,60, 2, pp. 91-110.
[19] Setiawan, A., \& Basuki, R. (2012). Pencocokan Citra Berbasis Scale Invariant FeatureTransfrom (SIFT) menggunakan Arc Cosinus. Jurnal Teknik Informatika S1 Udinus .

[20]Muklis. (2015). Implementasi Algoritma Affine Scale Invariant Feature Transfrom Untuk Pengenalan Wajah pada Citra Sketsa. Jakarta: Universitas Islam Negeri Syarif Hidayatullah.

[21]E. R. F. A. Putra, L. a. (2014). Aplikasi Automatic Image Stitching pada Kumpalan Gambar dalam Satu Scene. Student Journals Universitas Kristen Petra .

[22] Sungklok, C., Taemin, k., \& Wonpil, Y. (2009). Performance evaluation of RANSAC.

[23]Chen, J. S. (2010), a robust local image descriptor. EEE Trans. Pattern Anal. Mach. Intell .

[24]Ha, S.-W., \& Moon, Y.-H. (2011). Multiple Object Tracking Using SIFT Features and Location Matching. International Journal of Smart Home Vol. 5, No. 4 .

[25] Setiyawan, A., \& Ruri Suko Basuki, M. (2018). Pencocokan Citra Berbasis Scale Invariant Feature Transform (SIFT) menggunakan Arc Cosinus. JURNAL TEKNIK INFORMATIKA-S1 UDINUS . 